University for Business and Technology in Kosovo

UBT Knowledge Center

Oct 28th, 2:00 PM - 3:30 PM

\title{
Facebook as a New Media - Cultural and Communication Phenomenon of Globalization
}

\author{
Liljana Siljanovska \\ South East European University in Tetovo, I.siljanovska@seeu.edu.mk
}

Follow this and additional works at: https://knowledgecenter.ubt-uni.net/conference

Part of the Journalism Studies Commons

\section{Recommended Citation}

Siljanovska, Liljana, "Facebook as a New Media - Cultural and Communication Phenomenon of Globalization" (2017). UBT International Conference. 203.

https://knowledgecenter.ubt-uni.net/conference/2017/all-events/203

This Event is brought to you for free and open access by the Publication and Journals at UBT Knowledge Center. It has been accepted for inclusion in UBT International Conference by an authorized administrator of UBT Knowledge Center. For more information, please contact knowledge.center@ubt-uni.net. 


\title{
Facebook as a New Medium - Cultural and Communication Phenomenon of Globalization
}

\author{
Liljana Siljanovska, \\ South, East European University, Tetovo, Macedonia, \\ siljanovska@seeu.edu.mk
}

\begin{abstract}
The idea of this text is the method of textual analysis, using excerpts from academic research, but also by analyzing the extracts from the press, interpreting the sociological facts and opposing attitudes, to show the complexity of a phenomenon in an area and an activity that is very arbitrarily and irresponsibly used and interpreted. The Internet as a medium is a communication phenomenon in which the complex interconnection of the Facebook web site with real life itself transmits information to the participants and therefore requires a systematic analysis procedure that clarifies that complexity. As Vuksanovic emphasizes (2007), "the world of the apparition is again becoming actual." The Internet social communication is a supplement and extension of the traditional social behavior. It has been proven that the more individuals in communicative realities are connected, communicate tete-a-tete, they more commonly use other media for mutual communication, including Internet social communication. In fact, the new media, or social networks, upgrade traditional social behavior without having to increase or decrease it. The term "reality" is increasingly virtualized and falls under the influence of the media that is expressing the multifunctionality that gives dimension, shape and transforms the public. The theoretical reorganization of space and time generalizes the communication content and atomizes the audience through a dual approach that sets unwritten rules of communication culture. The Internet as an independent medium, which is partly composed of other media, due to the development of science and technology, on one hand, facilitates everyday life, and on the other hand, it does not make it stable and regulated, but it seems that it takes it away from everyday control. The consequences of the "Internet present" or "cyber reality" do not remain impressive and captured solely in such a virtual world, but also manifest themselves in the realms of communication in the real life.
\end{abstract}

Keywords: facebook, virtual, reality, internet, social, communication.

\section{Introduction}

The term "reality" falls under the influence of media, which, by doing so, carelessly, and very intrusively, falling under the influence of multiple impacts of globalization, creating cultural homogeneity. The Internet as an independent medium, which is partly constituted of other media, due to the development of science and technology, on the one hand, it facilitates everyday life, and on the other hand, it does not make it stable and regulated, but it seems that it takes it away from our control.The consequences of the "Internet present" or "cyber reality" do not remain noticed and trapped in such a virtual world, but they also manifest itself in the spheres of communication in "real life" and its actors. The Facebook site, more than anything else, can serve as a great example because it itself allows virtual interaction of people in countless fields that are not created 
exclusively from imaginary factors, but also in areas directly transferred from real life. There are countless examples related to this claim for a really special mediation between the real world and the virtual one, and through their special analysis follows the presentation of confronted attitudes on the issue of communitarian issues which is becoming more relevant.

„Facebook“, without a doubt, at first acts as a magical utopia of everyday life that abounds in nostalgia in a psychological sense that nowadays it is appropriate that the liberal desires and acts of the individual can only take place in the "free time" that is slowly disappearing. If we take into account that free time is now more precious compared to twenty or more years ago, the formation of Facebook can also be interpreted as a media message that is placed on the assault as an all-in-one product that can be used in various ways, while the time to use it remains a factor that limits but it contributes to the promotion of communication. The views on the issue of this intensively marketed product, which abounds with various types of user interaction, differ as much as the content itself that is plentiful. The concept of such a communication system may have been followed as "a reaction to the cultural backwardness of nations due to the advanced vulgarism, hypocrisy, and kitsch that are rapidly attacking the local societies"1. In the era of globalization, where it is less inclined to intervene in reality, it seems that "defense of culture poses a challenge to every conscious individual who promotes high ethical and aesthetic standards with his thought, attitude and work"2. What is "creative, intelligent, delicate, authentic, witty, and dignified" is moving in a direction independent of the ambitions of genius projects for which the notion of "distance" does not bind as some kind of coincidence. What is "sluggish, cheap, pathetic, buttered up, pretentious, ugly, and inhuman" 3 is the new description of the megalomania number of not only services but also the radically narrowed range of communication.

\section{Facebook as an integration of culture}

Culturologist and publicist Zorica Tomic, in the analysis of the "kniga na lica", states that "now the individual, besides having at least one mobile phone from which can not be taken away the first place as the medium of rapid communication, anyplace and anywhere has access to high-speed Internet where he can quickly reach his friends gathered at the only place to hang out on Facebook"4. Many people (and this most often refers to the population of people from eighteen to thirty-five years), believe that Facebook is a phenomenon of the new century because it manages to unite a large number of computer attractions, such as games, chat opportunities, uploading photographs, videos, music and much more. Despite, this narrowly positioned phenomenon of interpretation of unimaginable communication opportunities, the psychologists think that in the $21 \mathrm{st}$ century we are more than ever faced with the fact that we are lonely, because our contacts are getting weaker, even though we have a social obligation to communicate and for this we have a growing number of technical devices.Does Facebook then bring people together or do something contrary to it, and is our social life alarmedly degraded by this form of virtual communication? Is the true socializing of people face to face as a traditional, innate form of communication on the verge of extinction, and do the monitors threaten to become a total replacement for windows, streets, parks or restaurants?Facebook is really a planetary phenomenon. Consciously made to serve as a highly developed communication tool. It has features of a global epidemic. Because of the globalization and the accessibilityof the internet everywhere, it has spread to almost the entire planet (at least for the most part covered by the Internet), and for now, this epidemic cannot be stopped. Other analysts cite the Internet social communication as a supplement and extension of traditional social behavior. It has been proven that the more individuals in the organizations are connected, they communicate tete-a-tete, the more often they use other media for mutual communication, including 
internet social communication. In fact, the Internet upgrades traditional social behavior without having to increase or decrease it. Thinking about blogs on the Internet as for personal sites, i.e. sites that are of individuals or groups dealing with different activities, offer a variety of services and sell various products, they constantly call into question the positioning of communication and the preciousness of its existence in individuals in society. The development of the planet in a technological sense has shifted the boundaries of communication and, therefore, given it a tangled role that is becoming more complex every day.

\section{Virtual reality and public expression}

Through analyzing Facebook as a phenomenon, it seems that communicology as a branch of psychology and sociology is altered in the sense of its acknowledgment. Although it's easy to access and use, Facebook is actually a complex communication system that is jargonistic referred to as "social choreography" ${ }^{5}$ The flow of the messages goes from the center to the periphery, so that the person can not reverse the information or a person who communicates with many people. Its users do not, of course, fall into the category "chat/writing" in which communication is done in one direction, but it is a fact, however, that there are messages that are broadcasted through the site and which are not available for correction. When we take this into consideration and when we know that the majority of users on this site are not aware of the wide communication context that the site inevitably offers, it can not be ruled out that a small number of users will try to question all that is being offered, but risky, without even thinking, will miss the meaning of the messages that goes from the source to the goal, and thus will disable recognition and correction of prejudices and misunderstandings. From the side of the simple user, it will not be considered who the author of this virtual community is and for what purpose it is created / the user (the tenant) perceives it as a finished product and it is almost certain that the court of users can even come to its analysis and the meaning, the goal, would be insufficient. Scarce in the personal interpretations of such cyberspaces is based on the desire to consume the product to be fast, superficial and without articulated approach, and are for the sake of saving time which thus raises the destructive dose of social intolerance. Rolf Jensen, a philosopher of the media, wrote that people use the story to outline the values that they cherish. In a similar way, it contributes to fostering these values in real life as well as in the virtual. And with that in mind, people as actors on the Facebook scene are equal in the performance, which does not mean that the scene represents reality. So, a reality show in the true sense of the word (words). The camera does not shoot everything, the directors do not allow the audience to see and hear everything that is noticed. We censor our character, data, and works on Facebook, and we present it to the audience as much as we want to. It's neither good nor bad, but we do not remain anonymous. Consciously accepting the risk to make a name for ourselves some would continue to interpret it as a desire for exhibitionism. The space on Facebook is a kind of space for public exposure which gives the audience an opportunity to debate the question of our public recognition as an individual.Self-awareness, self-expression, self-assertion, self-image. The four "S", which are as old as the story of man. Today, less than ever we know who we are and seems to be in constant search for opportunities, ambient, situations in which we will receive a confirmed answer that someone has noticed us, that someone needs us, that someone desires our opinion and attention and that we are a person which opinion matters. Identity formation is a process through which everyone passes and everyone is unique. ${ }^{6}$ 


\section{Facebook and identity formation}

Facebook offers an express opportunity to form an identity, and it does it publicly. When discussing whether such action is rational, we can use the explanations of the sociologist Michel Lalnman, who does not say that "the individual acts in a rational way, even though norms actually have a value of coercion. If we assume that the prerequisites and objectives of the individuals are defined, then the participants also need to calculate the use of the funds. Accordingly, the selection of one course of action is actually rational." Will you really restore friendship with a person in the real world that after ten years you get in touch or not by means of this seemingly comprehensive medium inside the medium or virtually extended socializing will manage to satisfy your personal needs, it obviously depends but not on us only. Because the audience is an important factor in the creation of critical thinking, it is very important for us as individuals. In this case, the audience is composed of our "friends", we are the creators (entrepreneurs, builders, artists), and the work we do should present us and that is our 'profile' page. Within this current triad of artist-work-audience, the audience is "an active part of the process of creation, both the reception and the creation of the artwork" (the 'profile' page everything we are loading form) (Vuksanović, D. $)^{7}$ Each of us, individually and after (indefinite) time spent on the site, answers the question "Did Facebook make a change in your life? Does it make your contacts with your friends easier? Have you uploaded incorrect profile information? Do you think Facebook is used by lonely people only? Hidden or revealing, shameful and exhibitionistic, superficial an essential, tamed and liberating, captivating, creative and destructive, human and monkeyish, authentic and hidden-are only some dichotomies of the paradoxes of the "heavenly wines" (Adam and Eve lived in Heaven, naked and they did not care about the image) as a flow of communication that once seemed to be lacking as an additional factor that makes the identity of the individual more complete. With such reflections, and in particular by mentioning the terms "superficially," "creative," "liberating," the Facebook somehow takes the forms of Dadaism that are not entirely apathetic to anyone. The Dadaists (as well as Facebook users) sought to talk about their scandals and successes, to hold public discussions on all sorts of friends, so the writer and founder of Dadaism King, in a conversation with Roger Wittrak ${ }^{8}$, explained that he supports publicity and is not against success because they consider these two things to be elements of life that are as approachable as their opposites. Every Facebook user is in this sense is kind of a dadaist, but Facebook is in a strange way leading life and is expressed through social activities but through virtual ones.

The complex question of understanding the relationship between the individual and the community, and the even more complex question of understanding communication with these two factors of society, requires the processing of individuality and its deepest nature, and without very damaging consequences, publishing our profile on Facebook we come to the final goal, and that is to ensure that we have entered, and later and permanently remain in the memory of the people. By doing so, this site somewhat unobtrusively in this irregular world conceals a hiding place and way of communication much wider than the "verbal", photographic, and so on. When dancing in this virtual space, we should never forget the power, the truth, the seriousness, and the transcendence of this creative game that masking enables. Bearing in mind that the experiences of such a transfiguration can be harmless, the hidden human desires, his deep passions, and the delusions can swim to the surface. So even though Facebook acts as a protected platform for adventure of any kind, the view of one's own life form in society is changing and in a new and original way which marks the path that sociology and communicology will follow the path of globalization of society and new media. ${ }^{9}$ Or maybe the Facebook just comes down to the social game of interesting mechanics that excludes passion and values and slips away into the sphere of individual action. 
Conclusion: The objects of everyday life whose main and uninhabitable ingredient is the power of communication are as important as the "objects and phenomena" that fill the virtual world. The difference lies in the manner of accepting publicity and showing the sharp feeling of choosing from the offered. Through the communication of virtual verbal-art collages, gaining a feeling of protection and inferiority, there is no fear of verbal acts no matter who it reaches, communication can be broken due to skepticism and the fear of remark.

And, do we really want to be creative, intelligent, delicate, authentic, interesting and dignified? Do not we really want to be sluggish, cheap, pathetic, buttered up, pretentious,ugly, and inhuman? And what are we fighting for? Perhaps Facebook carries a true utopia in itself, because it harbors the need for repression, rather than profit for profit, at least for the most part. Such semiidealistic thinking has a lesser chance of survival in this world in which it is offered, and in fact, gives little to what is acceptable. A culture of dialogue such as Facebook, inevitably dictates the deconstruction of communication in the sense of its former understanding and the consequence of such a change will need to be studied and interpreted through the same principle. Through the principle of the phenomenon.

\section{Literature}

1. Bear, Henri and Karasu. DADA - Istorija na edna subverzija, Publishing Bookstore Zorana Stojanovića, Novi Sad, 1997.

2. Vukanovic, D. Filozofija na mediumite, FDA, Belgrade, 2007.

3. Kovacevic, I. Tradicija na modernoto, Ethnological Library, Belgrade, 2002.

4. Le Bon, G. Psihologija na tolpa, Belgrade, 2005.

5. Lich, E. Kultura i komunikacija, Library 20. Century, Belgrade 2002.

6. Mander, J. I Goldsmith, Globalizacija, Belgrade, 2005

7. Mandic, T. Komunikologija - Psihologija na komunikaciite, Clio, Belgrade, 2003 